\title{
Breakdown of Polyploidy and Isolation of Stable Polysomics in Amphidecaploid Avena sativa L. $\times A$. maroccana Gdgr.
}

\author{
Niti Kushwaha, Surinder N. Zadoo* and Rang N. Choubey \\ Indian Grassland and Fodder Research Institute, Jhansi-284003 India
}

Received July 7, 2003; accepted December 11, 2003

\begin{abstract}
Summary The study involves the chromosomal constitution of advanced progenies of amphidecaploid Avena sativa and A. maroccana. Amphidecaploid $2 n=10 x=70$ was raised from a pentaploid interspecific cross $A$. sativa $\times$ A. magna (Syn. A. maroccana). The selfed progenies of the amphiploid were scored for chromosomal constitution in $\mathrm{A}_{14}, \mathrm{~A}_{15}$ and $\mathrm{A}_{16}$ generations. It was observed that while there was a general breakdown and loss of chromosomes over the generations, but at the same time stable polysomics with $2 n=44,46,50,52,54,60,62,64,66$ and 68 were isolated together with progenies having female parent number of $2 n=6 x=42$ (A. sativa) and original decaploid number of $2 n=10 x=70$. No progenies with less than $2 n=6 x=42$ were recovered, although male parent happens to be a tetraploid with $2 n=4 x=28$. A general reduction in the number of multivalents and consequent increase in bivalent configurations was observed from $\mathrm{A}_{0}$ to $\mathrm{A}_{16}$ generations.
\end{abstract}

Key words Avena sativa, Avena maroccana, Polysomics, Amphiploidy, Interspecific hybridization, Oats.

Oats (Avena sativa L.) a constituent of family gramineae (Poaceae) is important in the sense that it ranks sixth in world cereal production and is widely cultivated for food, feed and fodder. The genus incorporates diploid, tetraploid and hexaploid species based on a basic chromosome number of $x=7$.

The wild tetraploid A. maroccana Gdgr. $(2 n=4 x=28)$ (Syn. A. magna Murph et. Terril), is cytogenetically and morphologically close to cultivated hexaploid $A$. sativa L. $(2 n=6 x=42)$ (Ladzinsky and Zohari 1971). Choubey et al. (1985), crossed the cultivated hexaploid A. sativa with tetraploid $(2 n=4 x=28)$ A. magna (Syn. A. maroccana), which resulted into sterile $\mathrm{F}_{1}$ pentaploid $(2 n=5 x=35)$. The $\mathrm{F}_{1}$ was carried forward by back crossing to $A$. sativa and in just two backcross generations stable hexaploid derivatives were isolated (Zadoo et al. 1988). Yet another approach adopted by said workers was restoration of fertility of $F_{1}$ pentaploid hybrid by doubling its chromosome number $(2 n=10 x=70)$ which would allow maximum recombination between parental genomes before stabilizing at hexaploid level. The chromosomal stability of selfed amphidecaploid generations was studied earlier by Pachauri et al. (1993) in $\mathrm{A}_{5}$ to $\mathrm{A}_{8}$ generations, and besides the normal number of $2 n=10 x=70$ and parental number of $2 n=6 x=42$ different polysomics including $2 n=43,44,46,54,58,62,64,66,68$ were also recorded. The present study involves the studies on chromosomal constitution of advanced generations $\left(\mathrm{A}_{14}\right.$ to $\left.\mathrm{A}_{16}\right)$ of the said amphidecaploid with particular reference to chromosome number, multivalent associations together with percent chromosomes involved in bivalent configurations.

\section{Materials and methods}

The material for the present study comprised of $\mathrm{A}_{14}$ to $\mathrm{A}_{16}$ progenies of amphidecaploid, $A$. sativa (UPO 94) $\times A$. maroccana Gdgr. The original cross $A$. sativa UPO $94(2 n=6 x=42) \times A$.

\footnotetext{
* Corresponding author, e-mail: snzadoo@igfri.up.nic.in
} 
magna (Syn. A. maroccana Gdgr.) was attempted in Oat improvement program of IGFRI way back in 1985 (Choubey et al. 1985). The fertility of sterile pentaploid hybrids was restored through chromosome doubling giving rise to fertile decaploid $(2 n=10 x=70)$ hybrids (Premachandran et al. 1986).

Panicles for meiotic studies were fixed and preserved in $1: 3$ glacial acetic acid:alcohol in which acetic acid component was saturated with ferric acetate for at least $48 \mathrm{~h}$ before the PMC's were smeared and stained in $2 \%$ acetocarmine. Studies were made from temporary slides and suitable cells were photographed using Olympus trinocular microscope with PM-6 photographic attachment.

\section{Results}

The meiotic studies of different progenies in $\mathrm{A}_{14}, \mathrm{~A}_{15}$ and $\mathrm{A}_{16}$ generations revealed that besides the original amphidecaploid number of $2 n=10 x=70$, individual plants/progenies with $2 n=42,43$, 44, 46, 50, 52, 54, 60, 62, 64, 66, 68 were recorded in different generations (Table 1, Figs. 1-11). Chromosomal associations of different polysomics in a particular generation were observed and pooled averages of different associations, along with range are given in Table 1, with special emphasis on percent chromosomes involved in bivalent configurations. The details of various polysomic derivatives are as under:

2n=43: A single plant with $2 n=43$ was observed in $\mathrm{A}_{16}$ generation which showed a regular chromosome association of 21 II +1 I (Fig. 2).

2n=44: 4,5 and 10 plants with $2 n=44$, were scored in $\mathrm{A}_{14}, \mathrm{~A}_{15}$ and $\mathrm{A}_{16}$ generations, respectively. The chromosomal associations ranged from 22 II to 2 IV + 18 II (Figs. 3-5). Percent chromosomes involved in bivalent configurations ranged from 97.04 to 98.54 .

2n=46: A total of 5 plants; 3 in $A_{15}$ and 2 in $A_{16}$ generation with $2 n=46$, were analyzed cytologically. Average chromosome associations were $0.47 \mathrm{IV}+0.04 \mathrm{III}+21.99 \mathrm{II}$ in $\mathrm{A}_{15}$ and $0.58 \mathrm{IV}+21.83 \mathrm{II}$ in $\mathrm{A}_{16}$ generation, respectively (Figs. 6, 7). Percent chromosomes involved in bivalent configurations ranged from 94.91 to 95.60 .

$\mathbf{2 n = 5 0 : ~} 4$ and 2 plants were scored in $\mathrm{A}_{15}$ and $\mathrm{A}_{16}$ generation, respectively, showing a chromosomal constitution of $2 n=50$ (Fig. 8). Average chromosome association was observed to be $0.74 \mathrm{IV}+0.055 \mathrm{III}+23.42 \mathrm{II}+0.11 \mathrm{I}$ in $\mathrm{A}_{15}$ and $0.88 \mathrm{IV}+23.23 \mathrm{II}$ in $\mathrm{A}_{16}$ generation. Bivalent configurations predominated and accounted for 93.68 and 92.92 percent chromosomes in $A_{15}$ and $A_{16}$ generations, respectively.

2n=52: A single plant in $\mathrm{A}_{16}$ generation with $2 n=52$ was observed and analyzed. Average chromosome association was $0.83 \mathrm{IV}+24.33 \mathrm{II}$, with bivalent configurations accounting for 93.57 percent chromosomes.

2n=54: A single plant with $2 n=54$ was observed in $\mathrm{A}_{15}$ generation. Average chromosome association was $0.85 \mathrm{IV}+25.30 \mathrm{II}$. Bivalent configurations accounted for 93.70 percent chromosomes.

2n=60: A total of 8 plants with $2 n=60\left(1\right.$ in $\mathrm{A}_{14}, 5$ in $\mathrm{A}_{15}, 2$ in $\mathrm{A}_{16}$ generation $)$ was analyzed cytologically. The plants from $\mathrm{A}_{15}$ and $\mathrm{A}_{16}$ generations showed only quadrivalent and bivalent configurations, whereas the only plant from $\mathrm{A}_{14}$ generation showed trivalent and univalent configurations also. The average number of quadrivalents ranged from 0.22 to 0.85 in different generations, whereas bivalent ranged from 28.30 to 29.29 (Table 1). Bivalent configuration predominated as in other polysomics.

2n=62: 5 plants with $2 n=62$, were analyzed in $A_{15}$ (2) and $A_{16}$ (3) generations. Average chromosomal association of $1.09 \mathrm{IV}+0.15 \mathrm{III}+28.51 \mathrm{II}+0.15 \mathrm{I}$ and $0.48 \mathrm{IV}+30.03 \mathrm{II}$ was observed in $A_{15}$ and $A_{16}$ generation, respectively. Bivalent configurations accounted for 91.96 and 96.87 percent chromosomes in the 2 generations, respectively. 
Table 1. Pooled chromosomal associations for different progenies over the generations

\begin{tabular}{|c|c|c|c|c|c|c|c|c|c|}
\hline \multirow{2}{*}{ S1. No. } & \multirow{2}{*}{ Generation } & \multirow{2}{*}{$\begin{array}{c}\text { Chromosome } \\
\text { No. }\end{array}$} & \multirow{2}{*}{ No. plants } & \multicolumn{5}{|c|}{ Chromosomal association } & \multirow{2}{*}{$\begin{array}{c}\% \\
\text { chromosomes } \\
\text { as II's }\end{array}$} \\
\hline & & & & VI & IV & III & II & I & \\
\hline 1 & $\mathrm{~A}_{14}$ & 42 & 62 & - & - & - & 21 & - & 100 \\
\hline 2 & $\mathrm{~A}_{15}$ & 42 & 109 & - & - & - & 21 & - & 100 \\
\hline 3 & $\mathrm{~A}_{16}$ & 42 & 112 & - & - & - & 21 & - & 100 \\
\hline 4 & $\mathrm{~A}_{16}$ & 43 & 1 & - & - & - & 21 & 1 & 97.67 \\
\hline 5 & $\mathrm{~A}_{14}$ & 44 & 4 & - & $\begin{array}{c}0.325 \\
(0-1)\end{array}$ & - & $\begin{array}{c}21.35 \\
(20-22)\end{array}$ & - & 97.04 \\
\hline 6 & $\mathrm{~A}_{15}$ & 44 & 5 & - & $\begin{array}{l}0.262 \\
(0-1)\end{array}$ & - & $\begin{array}{c}21.48 \\
(20-22)\end{array}$ & - & 97.63 \\
\hline 7 & $\mathrm{~A}_{16}$ & 44 & 10 & - & $\begin{array}{l}0.164 \\
(0-2)\end{array}$ & - & $\begin{array}{c}21.68 \\
(18-22)\end{array}$ & - & 98.54 \\
\hline 8 & $\mathrm{~A}_{15}$ & 46 & 3 & - & $\begin{array}{r}0.47 \\
(0-2)\end{array}$ & $\begin{array}{r}0.04 \\
(0-2)\end{array}$ & $\begin{array}{c}21.99 \\
(19-23)\end{array}$ & - & 95.60 \\
\hline 9 & $\mathrm{~A}_{16}$ & 46 & 2 & - & $\begin{array}{c}0.58 \\
(0-4)\end{array}$ & - & $\begin{array}{c}21.83 \\
(15-23)\end{array}$ & - & 94.91 \\
\hline 10 & $\mathrm{~A}_{15}$ & 50 & 4 & - & $\begin{array}{r}0.74 \\
(0-2)\end{array}$ & $\begin{array}{l}0.055 \\
(0-1)\end{array}$ & $\begin{array}{c}23.42 \\
(21-25)\end{array}$ & $\begin{array}{c}0.11 \\
(0-1)\end{array}$ & 93.68 \\
\hline 11 & $\mathrm{~A}_{16}$ & 50 & 2 & - & $\begin{array}{c}0.88 \\
(0-3)\end{array}$ & - & $\begin{array}{c}23.23 \\
(19-25)\end{array}$ & - & 92.92 \\
\hline 12 & $\mathrm{~A}_{16}$ & 52 & 1 & - & $\begin{array}{r}0.83 \\
(0-2)\end{array}$ & - & $\begin{array}{c}24.33 \\
(22-26)\end{array}$ & - & 93.57 \\
\hline 13 & $\mathrm{~A}_{15}$ & 54 & 1 & - & $\begin{array}{r}0.85 \\
(0-2)\end{array}$ & - & $\begin{array}{c}25.30 \\
(23-27)\end{array}$ & - & 93.70 \\
\hline 14 & $\mathrm{~A}_{14}$ & 60 & 1 & - & $\begin{array}{c}0.22 \\
(0-1)\end{array}$ & $\begin{array}{c}0.22 \\
(0-1)\end{array}$ & $\begin{array}{c}29.11 \\
(28-30)\end{array}$ & $\begin{array}{r}0.22 \\
(0-1)\end{array}$ & 97.03 \\
\hline 15 & $\mathrm{~A}_{15}$ & 60 & 5 & - & $\begin{array}{r}0.35 \\
(0-1)\end{array}$ & - & $\begin{array}{c}29.29 \\
(28-30)\end{array}$ & - & 97.63 \\
\hline 16 & $\mathrm{~A}_{16}$ & 60 & 2 & - & $\begin{array}{r}0.85 \\
(0-2)\end{array}$ & - & $\begin{array}{c}28.30 \\
(26-30)\end{array}$ & - & 94.33 \\
\hline 17 & $\mathrm{~A}_{15}$ & 62 & 2 & - & $\begin{array}{r}1.09 \\
(0-2)\end{array}$ & $\begin{array}{r}0.15 \\
(0-2)\end{array}$ & $\begin{array}{c}28.51 \\
(25-31)\end{array}$ & $\begin{array}{r}0.15 \\
(0-2)\end{array}$ & 91.96 \\
\hline 18 & $\mathrm{~A}_{16}$ & 62 & 3 & - & $\begin{array}{r}0.48 \\
(0-2)\end{array}$ & - & $\begin{array}{c}30.03 \\
(27-31)\end{array}$ & - & 96.87 \\
\hline 19 & $\mathrm{~A}_{15}$ & 64 & 4 & - & $\begin{array}{r}0.74 \\
(0-2)\end{array}$ & $\begin{array}{c}0.08 \\
(0-1)\end{array}$ & $\begin{array}{c}30.48 \\
(29-32)\end{array}$ & $\begin{array}{r}0.08 \\
(0-1)\end{array}$ & 95.25 \\
\hline 20 & $\mathrm{~A}_{16}$ & 64 & 5 & - & $\begin{array}{r}0.80 \\
(0-2)\end{array}$ & $\begin{array}{r}0.02 \\
(0-2)\end{array}$ & $\begin{array}{c}30.34 \\
(28-32)\end{array}$ & $\begin{array}{r}0.13 \\
(0-2)\end{array}$ & 94.81 \\
\hline 21 & $\mathrm{~A}_{15}$ & 66 & 3 & - & $\begin{array}{r}1.05 \\
(0-4)\end{array}$ & $\begin{array}{r}0.35 \\
(0-2)\end{array}$ & $\begin{array}{c}30.34 \\
(21-33)\end{array}$ & $\begin{array}{r}0.13 \\
(0-2)\end{array}$ & 91.93 \\
\hline 22 & $\mathrm{~A}_{16}$ & 66 & 2 & - & $\begin{array}{r}0.67 \\
(0-2)\end{array}$ & $\begin{array}{r}0.06 \\
(0-1)\end{array}$ & $\begin{array}{c}31.52 \\
(29-33)\end{array}$ & $\begin{array}{r}0.04 \\
(0-2)\end{array}$ & 95.51 \\
\hline 23 & $\mathrm{~A}_{16}$ & 68 & 2 & - & $\begin{array}{r}1.17 \\
(0-2)\end{array}$ & $\begin{array}{r}0.07 \\
(0-2)\end{array}$ & $\begin{array}{c}31.44 \\
(29-34)\end{array}$ & $\begin{array}{r}0.04 \\
(0-2)\end{array}$ & 92.47 \\
\hline 24 & $\mathrm{~A}_{15}$ & 70 & 3 & $\begin{array}{l}0.026 \\
(0-1)\end{array}$ & $\begin{array}{r}1.63 \\
(0-5)\end{array}$ & $\begin{array}{r}0.49 \\
(0-2)\end{array}$ & $\begin{array}{c}30.83 \\
(22-35)\end{array}$ & $\begin{array}{r}0.19 \\
(0-2)\end{array}$ & 88.08 \\
\hline 25 & $\mathrm{~A}_{16}$ & 70 & 3 & - & $\begin{array}{c}0.9 \\
(0-3)\end{array}$ & $\begin{array}{r}0.09 \\
(0-1)\end{array}$ & $\begin{array}{c}32.97 \\
(29-35)\end{array}$ & $\begin{array}{r}0.21 \\
(0-2)\end{array}$ & 94.20 \\
\hline $26^{*}$ & $\mathrm{~A}_{0}$ & 70 & Plant 1 & 0.59 & 2.09 & 0.14 & 28.7 & 0.13 & 82.00 \\
\hline $27 *$ & $\mathrm{~A}_{0}$ & 70 & Plant 2 & 0.07 & 1.77 & 1.4 & 28.56 & 1.3 & 81.62 \\
\hline
\end{tabular}

* From Premachandran et al. 1986. 

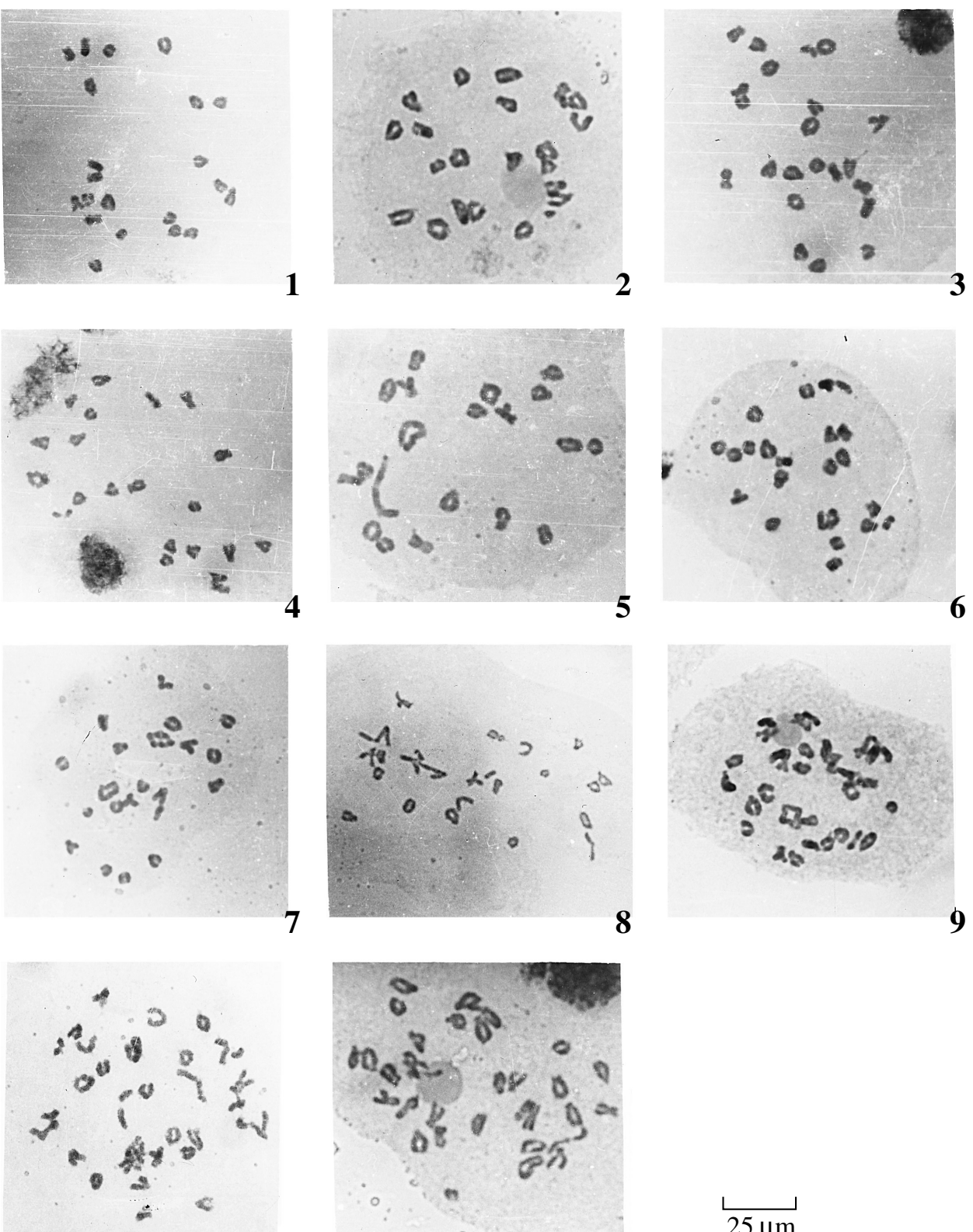

10

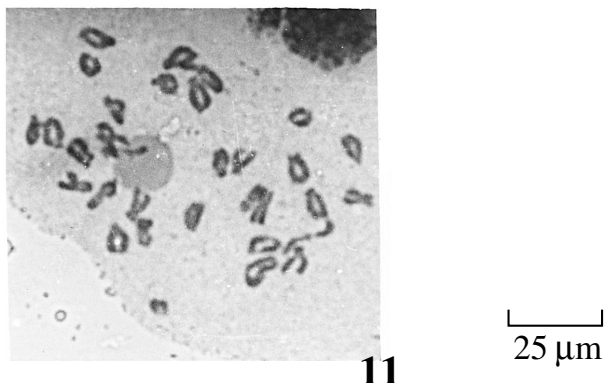

Figs. 1-11. 1) $2 n=42,21 \mathrm{II}$; 2) $2 n=43,21 \mathrm{II}+1 \mathrm{I}$; 3) $2 n=44$, 22 II; 4) $2 n=44,1$ IV+20 II; 5) $2 n=44$, $2 \mathrm{IV}+18 \mathrm{II}$; 6) $2 n=46,1 \mathrm{IV}+21 \mathrm{II}$; 7) $2 n=46,4 \mathrm{IV}+15 \mathrm{II}$; 8) $2 n=50$, 2 IV + 21 II; 9) $2 n=64$, 1 IV + 30 II; 10) $2 n=68,34$ II; 11) $2 n=70,1$ IV +33 II.

2n=64: 9 plants with $2 n=64$ from $\mathrm{A}_{15}$ and $\mathrm{A}_{16}$ generations were analyzed for chromosomal configurations. Average associations were observed to be $0.74 \mathrm{IV}+0.08 \mathrm{III}+30.48 \mathrm{II}+0.08 \mathrm{I}$ and $0.80 \mathrm{IV}+0.02 \mathrm{III}+30.34 \mathrm{II}+0.13 \mathrm{I}$ in $\mathrm{A}_{15}$ and $\mathrm{A}_{16}$ generation, respectively. Bivalent configurations accounted for 95.25 and 94.81 percent chromosomes in $\mathrm{A}_{15}$ and $\mathrm{A}_{16}$ generation, respectively (Fig. 9, Table 1).

2n=66: 3 plants from $A_{15}$ and 2 from $A_{16}$ generation showed a chromosome constitution of $2 n=66$. Average association per cell was $1.05 \mathrm{IV}+0.35 \mathrm{III}+30.34 \mathrm{II}+0.13 \mathrm{I}$ in $\mathrm{A}_{15}$ and 
$0.67 \mathrm{IV}+0.06 \mathrm{III}+31.52 \mathrm{II}+0.04 \mathrm{I}$ in $\mathrm{A}_{16}$, generation.

2n=68: 2 plants with $2 n=68$ in $\mathrm{A}_{16}$ generation were isolated and analyzed (Fig. 10). Average chromosome association was found to be $1.17 \mathrm{IV}+0.07 \mathrm{III}+31.44 \mathrm{II}+0.04 \mathrm{I}$. Bivalent configuration accounted for 92.47 percent chromosomes.

2n=70: 6 plants, 3 each from $A_{15}$ and $A_{16}$ generation with original euploid number of $2 n=10 x=70$ were analyzed cytologically (Fig. 11). Average chromosome associations were $0.026 \mathrm{VI}+1.63 \mathrm{IV}+0.49 \mathrm{III}+30.83 \mathrm{II}+0.19 \mathrm{I}$ and $0.9 \mathrm{IV}+0.09 \mathrm{III}+32.97 \mathrm{II}+0.21 \mathrm{I}$ in $\mathrm{A}_{15}$ and $\mathrm{A}_{16}$ generation, respectively. The bivalent configurations accounted for 88.08 and 94.20 percent chromosomes in $\mathrm{A}_{15}$ and $\mathrm{A}_{16}$ generation, respectively.

\section{Discussion}

The genus Avena L. has been extensively studied for its cytogenetic attributes and species relationships. It encompasses a polyploid series with diploid $(2 n=14)$, tetraploid $(2 n=28)$ and hexaploid $(2 n=42)$ species. A. sativa L. a hexaploid species is the most common cultivated form. Most of the species of the genus are wild and weedy, and constitute a rich repository of genes, that can be tapped for improvement of cultivated oats. However, successful gene transfer depends upon homology and/or homoeology between chromosomes of wild and cultivated species, which can be effectively used for introgression of desirable traits into cultivated oats.

The material for the present studies comprised of $\mathrm{A}_{14}$ to $\mathrm{A}_{16}$ progenies of the amphidecaploid, A. sativa $\times$ A. maroccana $(2 n=10 x=70)$ raised by Premachandran et al. (1986) from the colchicine treatment of pentaploid $F_{1}$ hybrid of the said parentage. As reported earlier (Pachauri et al. 1993) there has been a steady breakdown of amphidecaploid, with the loss of chromosomes over the generations, and first stable hexaploids were recorded from $\mathrm{A}_{5}$ generation onwards. Besides the stable hexaploids, incorporating morphological features of both the parents, some progenies with chromosome numbers, as high as $2 n=54,58,62,66,68$ as well as the normal amphidecaploid number of $2 n=10 x=70$ were also recorded (Pachauri et al. 1993). It is interesting to note that in the selfed progenies $\left(\mathrm{A}_{1}\right.$ to $\left.\mathrm{A}_{16}\right)$ of amphidecaploid $(2 n=10 x=70)$ no progeny was observed with chromosome number less than $2 n=6 x=42$, the number of female parent of the said cross, which leads one to speculate that cytoplasm of the female parent $(2 n=6 x=42)$ may have a role in resolution of chromosome number at hexaploid level. However, studies on back cross progenies tend to show that progeny resolves towards the chromosome number of recurrent parent. The back cross progenies of pentaploid hybrid with $A$. sativa resulted in stabilization of chromosomes at hexaploid level of $A$. sativa in just 2 back crosses (Zadoo et al. 1988). Whereas, earlier studies on the same species combination hybrid by Ladizinsky and Fainstein (1977) showed the recovery of tetraploid progenies upon back crossing with $A$. maroccana $(2 n=4 x=28)$, which leads to the conclusion that genotype of recurrent parent plays a role in stabilization of chromosome number.

While isolation and identification of stable hexaploids, and a series of polysomics with $2 n=42$, 43, 44, 46, 58, 62, 64, 66, 68 and 70 have been reported (Pachauri et al. 1993). The present study was undertaken to find out the stability of polysomics in $\mathrm{A}_{14}$ to $\mathrm{A}_{16}$ generation, together with details of their cytological behavior with particular reference to multivalent formation.

In the present studies individual progenies with $2 n=42,44,46,50,60,64,68$ and 70 were identified in $\mathrm{A}_{14}$ generation, whose progenies in most of the cases, were in turn scored in $\mathrm{A}_{15}$ and $\mathrm{A}_{16}$ generations. In subsequent generations, besides the numbers noted in $\mathrm{A}_{14}$ generation plant progenies with $2 n=43,52,54,62$ and 68 were identified. By far the most stable lines were with $2 n=42$, 44 and 46 . The lines with $2 n=42$ showed a stable meiotic behaviour with 21 bivalents, followed by regular disjunction of chromosomes. Such lines were not akin to hexaploid A. sativa in their morphological features, and in all cases incorporated the characters of tetraploid parent A. maroccana.

The mechanism of elimination of chromosomes is not clear. Katsiotis and Forsberg (1994) re- 
ported that within the same anther, in synthetic Avena octoploids, the chromosome number of meiocytes was not always same. Chromosome number ranged from 50 to 56, though more than half of the meiocytes contained full octoploid complement of $2 n=56$, however, fewer than 56 chromosomes were also observed in meiocytes. The instability of chromosome number in pollen mother cells has not however, been recorded in our studies. As in the case of octoploids studied by Katsiotis and Forsberg (1994), no visible spindle differences were observed in PMC's during the course of present study, as such mechanism of loss of chromosomes during subsequent generations is not clearly understood. Ladizinsky and Fainstein (1977) found a great variation in the chromosomes contributed by female parent in crosses involving, $\mathrm{F}_{1}$ hybrid, pentaploid $\times$ hexaploid parent and pentaploid $\times$ tetraploid parent. The contribution of female parent was determined by deducing the number contributed by known male parent from chromosome number of back cross progeny. The extent of variation was found to be from 12 to 48 chromosomes. It is thus apparent that female gamete can sustain a considerable loss/gain of chromosomes, probably due to enough duplicated genetic material present in the genome which acts as a buffer to chromosome loss, at the same time the presence of enough duplicated material in gametes with higher number also does not have any aberrant effect.

The mechanism of chromosome elimination in interspecific hybrids is quite rampant. In interspecific hybrids between Hordeum bulbosum L. $\times H$. vulgare L. the genome of $H$. bulbosum is completely eliminated in early stages of embryo development (Davies 1974). Similarly chromosomes of Nicotiana plumbaginifolia Viv. are eliminated from interspecific hybrid $N$. tabacum L. $\times N$. plumbaginifolia Viv. (Davies 1974). In the present studies chromosome eliminations during Decaploid-Octoploid-Hexaploid descent appears to be due to selective elimination of tetraploid complement contributed by $A$. maroccana, and stability at hexaploid level, as no further breakdown has been observed.

Different polysomics reported earlier in $\mathrm{A}_{5}$ to $\mathrm{A}_{8}$ generation of the material under study include $2 n=43,44,46,54,58,62,64,66$ and 68 (Pachauri et al. 1993). In the present studies on $A_{14}$ to $\mathrm{A}_{16}$ generation of the same material additional lines with 50,52 and 60 have been isolated. The study over the generations revealed that lines with $2 n=42,44,46,64$ and 70 have more or less stabilized, over the generations. It is interesting to observe that but for $2 n=43$, no plant with odd number of chromosomes has been isolated. Predominant bivalent pairing indicates that there is some sort of selective elimination of chromosomes, and during the process of breakdown probably it is the pairs of chromosomes that are eliminated rather than single chromosome. This is further corroborated by a progressive series of polysomics from 42 to 70 i.e. 42, 44, 46, 50, 52, 54, 60, 62, 64, 66,68 and 70 together with very low frequency of univalent configuration in different plants/progenies.

Compared to $\mathrm{A}_{0}$ (Premachandran et al. 1986) the percentage of chromosomes involved in bivalent configurations in decaploids has increased considerably i.e. from $81-82 \%$ to $88.08-94.20 \%$ in $\mathrm{A}_{15} / \mathrm{A}_{16}$ generation. Increase in bivalent configuration and consequent decrease in multivalent configurations is in conformity with earlier reports on autotetraploids of Brassica campestris var. Toria (Swaminathan and Sulbha 1959). It is apparent that in the present material there is a progressive allopolyploidization of the original $2 n=10 x=70$, though in strict terms it is an allopolyploid, but due to residual intergenomal homology a few multivalent association are encountered which show a definite trend of reduction from $A_{0}$ to $A_{16}$ as is apparent by the increase in percentage of chromosomes involved in bivalent configurations.

The repository of polysomics isolated from the amphiploid $A$. sativa $\times A$. maroccana will be useful in further genetic studies and transfer of desirable traits from wild to cultivated oats, after characterization of the generated material. 


\section{Acknowledgements}

The authors are thankful to Director, IGFRI, Jhansi, for the facilities and encouragement during the course of present work.

\section{References}

Choubey, R. N., Premachandran, M. N. and Gupta, S. K. 1985. Effect of Avena sativa genotype 'JHO-801' on chromosomal association in interspecific hybrid with A. magna. Indian J. Genet. 45: 138-140.

Davies, D. R. 1974. Chromosome elimination in interspecific hybrids. Heredity 32: 267-270.

Katsiotis, A. and Forsberg, R. A. 1994. Cytogenetic studies of synthetic Avena octoploid lines. J. Genet. and Breed. 48: 415-422.

Ladizinsky, G. and Fainstein, R. 1977. Introgression between the cultivated hexaploid oat Avena sativa and the tetraploid wild A. magna and A. murphyi. Can. J. Genet. Cytol. 19: 59-66.

- and Zohari, D. 1971. Notes on species delimitation, species relationships and polyploidy in Avena L. Euphytica 20: 380-395.

Pachauri, A., Zadoo, S. N. and Choubey, R. N. 1993. Cytological status of amphiploid progenies of Avena sativa L. $\times$ A. maroccana Gdgr. Neo-botanica 1: 55-62.

Premachandran, M. N., Choubey, R. N. and Gupta, S. K. 1986. Morphology, cytology and fertility of Avena sativa L., A. magna Murph. et. Terrel. amphiploids. Plant Breeding 97: 268-271.

Swaminathan, M. S. and Sulbha, K. 1959. Multivalent frequency and seed fertility in raw and evolved tetraploids of Brassica campestris var. Toria. Z. Vererbungs. 90: 385-392.

Zadoo, S. N., Choubey, R. N., Gupta, S. K. and Premachandran, M. N. 1988. Chromosomal stability in the back cross progenies of the pentaploid hybrids between Avena sativa L. and A. maroccana Gdgr. Plant Breeding 100: 316-319. 